Review

\title{
A comprehensive review of polysaccharide-based bionanocomposites for food packaging applications
}

\author{
Aayeena Altaf ${ }^{1} \cdot$ Zakiya Usmani $^{2} \cdot{\text { Aamir Hussain } \text { Dar }^{3} \cdot \text { Kshirod K. Dash }}^{4}$
}

Received: 27 November 2021 / Accepted: 9 February 2022

Published online: 24 February 2022

(c) The Author(s) 2022 OPEN

\begin{abstract}
The newly engineered functional systems of nanotechnology implemented in food packaging minimize food product loss by extending shelf life. The incorporation of nanostructured materials into packaging formulations enhanced the existing characteristics of food packaging materials by increasing the specific surface area of these biopolymers. Natural biopolymers were regarded as greener, more sustainable, and environmentally friendly materials. Starch nanocrystals have been employed effectively as fillers in polymer matrices to enhance mechanical and moisture barrier characteristics. Both chitin and chitosan nanoparticles were biocompatible, biodegradable, inexpensive in cost, and mucoadhesive in nature. Alginate nanoparticles demonstrated high thermal and chemical stability. Because of these features, polysaccharide-based nanoparticles were excellent candidates for nano reinforcements in bio-nanocomposites. The nano sized forms of starch, chitin, chitosan, and alginate are non-toxic and antimicrobial. This study focused on current advances in the development of food packaging films based on starch, chitin, chitosan, and alginate nanoparticles, as well as trends and challenges in the formulation of bio-based polymers. This review detailed the synthesis of starch, chitin, chitosan, and alginate nanoparticles using various techniques such as hydrolysis, ionic gelation, reverse micellization, emulsification, and crosslinking. This type of polysaccharide-based bio-nanocomposite is expected to revolutionize the entire food packaging industry.
\end{abstract}

Keywords Nanotechnology · Food packaging $\cdot$ Chitin · Starch $\cdot$ Chitosan · Alginate $\cdot$ Ionic gelation · Crosslinking

\section{Introduction}

The primary role of food packaging is to protect the product and maintain its shelf life. The food contained within the package should be safe and of acceptable quality. The food industry is continually searching for new technologies to improve and promote additional packaging aspects, such as traceability, microbial growth prevention, and food safety. The application of nanostructured materials in packaging materials can improve the existing qualities of food packaging materials [1]. Nanostructured materials are those in which the structural constituents have at least one dimension in nanometric scale and the diameters ranging from 1 to $100 \mathrm{~nm}$. Nanostructured materials include nanoparticles, nanorods, nanowires, thin films, and bulk materials made from nanoscale building blocks or containing nanoscale

Aamir Hussain Dar, daraamirft@gmail.com; $\bowtie$ Kshirod K. Dash, kshirod@tezu.ernet.in | Department of Food Technology, School of Interdisciplinary Studies, Jamia Hamdard, New Delhi, India. ${ }^{2}$ Department of Pharmaceutical Sciences, Lingayas Vidyapeeth,

Faridabad, Haryana 121002, India. ${ }^{3}$ Department of Food Technology, Islamic University of Science and Technology, Kashmir 192122, India. ${ }^{4}$ Department of Food Processing Technology, Ghani Khan Choudhury Institute of Engineering and Technology, Narayanpur, Malda, West Bengal 732141, India.

Discover Food $\quad$ (2022) 2:10 | https://doi.org/10.1007/s44187-022-00011-x 
features. Nanostructured materials are categorized as zero-dimensional (nanoclusters, quantum dots, fullerenes), onedimensional (nanorods, nanotubes), two-dimensional (ultrafine-grained over layers, thin films), or three-dimensional (particles, nanocomposites, dendrimers) nanomaterials. Nanotechnology has paved the way for the use and development of novel nanostructured materials known as nanomaterials in the food packaging sector.

The packaging system provides protection, containment, distribution, transportation, and identification of food materials along the supply chain from farm to fork. The conventional materials used in food packaging are non-biodegradable petroleum and plastic polymers, leading to severe effects on the global environment. As a result, the usage of biodegradable packaging materials made from recyclable resources can minimize environmental consequences while increasing waste utilization from agro-based sectors. Agriculture and food product wastes are examples of biodegradable waste, from which materials such as polysaccharides, cellulose, silica-based materials, etc., can be obtained and utilized in the production of nanomaterials for food packaging systems. Therefore, nanomaterials based on naturally derived polymers can increase the quality of biodegradable and edible food packaging materials, which are considered more environmentally friendly than that other traditional packaging films [2].

The quality and freshness of the product are maintained in the time of commercialization and consumption by an accurate selection of packaging material and technology. Incorporating nanoparticles into polymer matrices can assist in maintaining these properties in food packaging materials [3]. Nanomaterials provide a range of functional characteristics in the packaging, such as improving thermal, barrier, and mechanical properties. Therefore there is a growing need for nanomaterials in food system packaging. Nanomaterials are used in food items to modulate the release of antioxidants, flavors, enzymes, and antimicrobials [4]. Nanomaterials included in food packaging materials release active ingredients in a regulated manner and prevent food spoiling [5]. As a result, nanomaterials in food packaging enhance the usage of biodegradable materials in packaging, reduce wastage of processed foods, preserve food freshness, and increase shelf life $[6,7]$.

Polysaccharides are abundant are the most abundant carbohydrates in nature and can be obtained from plants, animals, and microbes. Polysaccharides have intrinsic properties such as biodegradability, biocompatibility, and nontoxicity, making them suitable for use in food packaging. Polysaccharides are large, high-molecular-weight compounds generated by glycosidic bonds connecting monosaccharide units. The various natural biopolymer for the formation of bio nanocomposites for food packaging applications are presented in Fig. 1. The most common polysaccharides used in food packaging include starch, cellulose, chitin, chitosan, alginate, and hyaluronic acid. These polysaccharide-based nanoparticles can be used as fillers to improve the physical properties of biopolymers.

The application of bio-nano composites in industrial packaging is being researched as part of the continuous quest for novel solutions for efficient and sustainable systems. Bio-nanocomposites are eco-friendly components made from biodegradable and renewable material and hence referred to as green nanocomposites. Bio-nano composites have antibacterial characteristics that allow them to inactivate bacteria more efficiently due to the increased surface-to-volume ratio and higher surface reactivity of the nanosized antimicrobial agents. On this basis, this review was conducted on the synthesis of polysaccharide (starch, chitosan, chitin, and alginate) nanoparticles and the development of bio-nano composites integrating polysaccharide-based nanoparticles into the biopolymeric matrices. The techniques for the synthesis

Fig. 1 Various natural biopolymer for the formation of bionanocomposites for food packaging applications

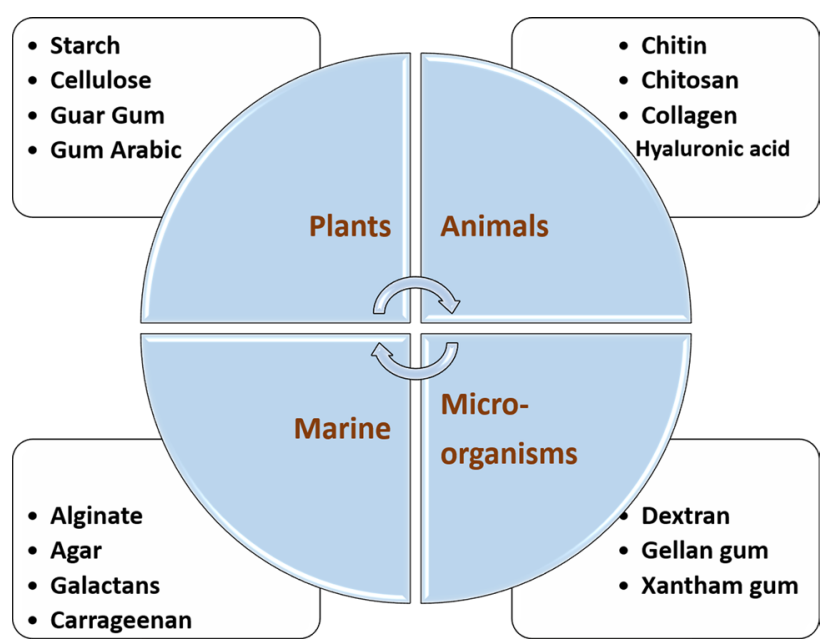


of starch, chitosan, chitin, and alginate nanoparticles and their applications for enhancing the properties of packaging films are covered in this review.

\section{Type of review and search strategy}

This review addressed the literature on polysaccharide-based bionanocomposites in an integrated manner, allowing for developing novel frameworks and perspectives on the theme. In order to improve the understanding of the phenomenon of bionanocomposites, this review combines both experimental and theoretical research conducted in the area. Different databases were used to arbitrate various intellectual studies, including journal articles, conference proceedings, and books. To ensure adequate and efficient coverage of the research topic and literature review, databases such as Scopus, Web of Science, and Google scholar were used for the searches. A few of the search strategy strategies used were online searching with keywords, specific phrases, and subject headings. A bibliographic approach strategy was used in this review for the literature search.

\section{Polysaccharide-based nanoparticles for food packaging}

Polysaccharide-based NPs are made from natural biomaterials like polysaccharides, decreasing toxicity, biodegradability, and physiological stability concerns. Polysaccharides are abundant in nature, making them low-cost biomaterials to investigate. This review discusses the synthesis and application of starch, chitin, chitosan, and alginate nanoparticles in food packaging films. The different methods of preparation of polysaccharide nanoparticles are presented in Fig. 2. Starch-based nanosystems are frequently classified into two types such as starch nanocrystals and starch nanoparticles. A number of processes, including acid or enzymatic hydrolysis and physical disintegration, can be used to create starch nanocrystals and nanoparticles. The acid hydrolysis process yields starch nanocrystals with high crystallinity and a platelet-like shape by hydrolyzing the amorphous component of the starch granules. Starch nanoparticles are completely amorphous particles produced by controlled nanoprecipitation of gelatinized starch. It has been observed that starch nanoparticles have larger particle sizes than starch nanocrystals and that their size and shape may be adjusted by the synthesis procedure in both situations. In several contexts, starch nanoparticles and starch nanocrystals are considered synonymous since both terms relate to the crystalline components of starch that remain after hydrolysis or other physical treatments. Starch nanocrystals and nanoparticles have been employed effectively as fillers in polymer matrices to improve mechanical and barrier characteristics. Different methods of preparing starch nanoparticles from various starch sources are presented in Table 1.

\subsection{Starch nanocrystals}

Starch nanocrystals are semi-crystalline platelets of starch granules formed by hydrolysis with sulfuric acid in amorphous areas. They have different sizes depending upon the source of starch; e.g., the sizes of starch nanocrystals obtained from potato starch, pea starch, and maize starch are 40-70 nm, 60-150 nm, and 70-100 nm, respectively [8]. Hydrolysis of nanocrystals is usually performed below gelatinized temperature. The size and yield of starch nanocrystals are highly affected by the conditions of hydrolysis during the extraction process. The structure and morphology of starch nanocrystals are mainly determined by crystallinity and the relative proportion of amylose and amylopectin content. Starch nanocrystals are used as filler components in polymeric matrices to increase the tensile strength of packaging film. Starch nanocrystals also reduced the oxygen transfer rate and water vapor permeability of packaging film. The addition of $5 \%$ maize starch nanocrystals produced by acid hydrolysis to pea-starch films enhanced tensile strength by around $72 \%$ [9]. The inclusion of starch nanocrystals had a significant influence on the characteristics of Polycaprolactone, increasing the tearing strength from 37 to $45 \mathrm{kN} / \mathrm{m}$ and decreasing the oxygen transmission rate from 1740 to $1250 \mathrm{~cm}^{3} / \mathrm{m}^{2}$ day [10]. The inclusion of $5 \%$ starch nanocrystals to mango kernel starch films enhanced the tensile strength by around $90 \%$ and elastic modulus by $120 \%$ while lowering the water vapor permeability by approximately $15 \%$ [11]. There are three methods that are used to synthesize nanocrystals, which include (i) hydrolysis, (ii) the Regeneration/ nanoprecipitation process, and (iii) physical methods. 


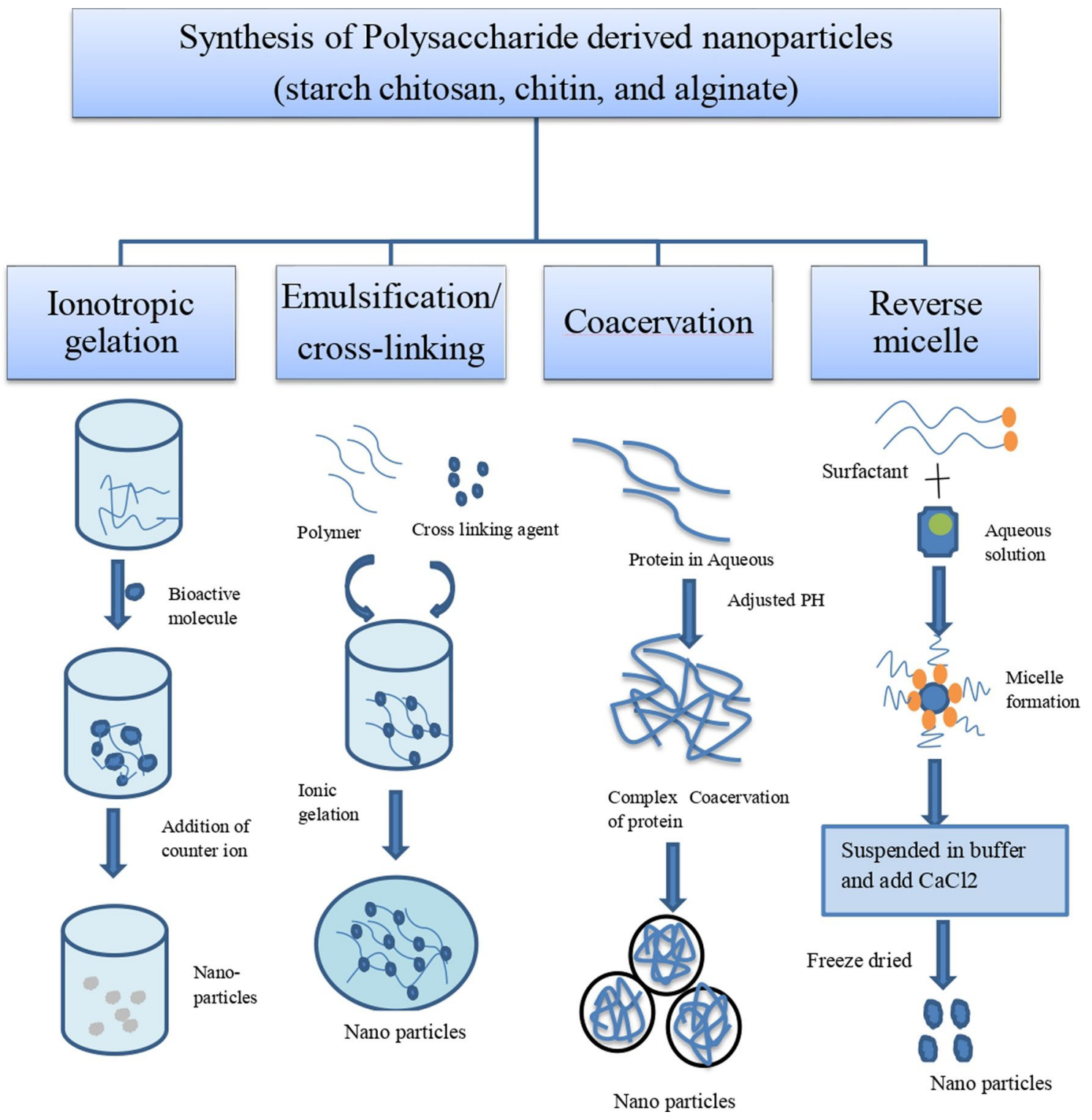

Fig. 2 Method of preparation of polysaccharide nanoparticles

\subsubsection{Hydrolysis method for starch nanocrystals}

3.1.1.1 Acid hydrolysis A method commonly used to create starch nanocrystals is acid hydrolysis. There are two stages of acid hydrolysis in starch nanocrystal formation: the first stage involves hydrolysis at a very fast rate, and in the second stage, the rate of hydrolysis is slow, while some studies have proven that acid hydrolysis is completed in three stages: rapid, slow, and very slow. Rapid hydrolysis attacks amorphous parts of the granule of the starch, while as slow hydrolysis involves erosion of the crystalline regions [12]. Acid hydrolysis involves dilution of starch by hydrochloric or sulfuric acid with continuous stirring for a long time under controlled temperature followed by centrifugation and washing with distilled water for differentiation of starches from acid. Starch nanocrystals developed by acid hydrolysis possess high crystallinity. To isolate the crystalline regions from starch granules, acids such as sulfuric acid or hydrochloric acid are used at low temperatures, usually below the gelatinization temperature. Low temperature prevents starch breakdown and starch gelatinization. There is rapid hydrolysis in the amorphous regions compared to crystalline regions [13]. After acid hydrolysis, the residue comprises highly crystalline nanocrystals with nanoscale morphology. The acid hydrolysis process is affected by the type of acid and the duration of the hydrolysis. Some studies have revealed that 15 days require hydrolysis by $\mathrm{HCl}$, while seven days are required for $\mathrm{H}_{2} \mathrm{SO}_{4}[14]$. 
Table 1 Different methods of preparation of starch nanoparticles from various starch source

\begin{tabular}{|c|c|c|c|}
\hline Source of starch & Preparation method & Condition for making nano starch & References \\
\hline Waxy corn starch & Acid hydrolysis & $\begin{array}{l}2.2 \mathrm{~mol} / \mathrm{L} \mathrm{HCl} \text { at } 36^{\circ} \mathrm{C} \text { for } 40 \text { days } \\
3.16 \mathrm{~mol} / \mathrm{L} \mathrm{H}_{2} \mathrm{SO}_{4} \text { at } 40 \text { oC for } 5 \text { days }\end{array}$ & {$[31]$} \\
\hline Corn starch & Acid hydrolysis & $2.87 \mathrm{~mol} / \mathrm{L} \mathrm{H}_{2} \mathrm{SO}_{4}$ at $45 \mathrm{oC}$ for 7 days & {$[32]$} \\
\hline Pea starch & Acid hydrolysis & $3.16 \mathrm{~mol} / \mathrm{LH}_{2} \mathrm{SO}_{4}$ at 40 oC for 5 days & [33] \\
\hline Potato starch & Acid hydrolysis & $2.2 \mathrm{~mol} / \mathrm{L} \mathrm{HCl}$ at $36^{\circ} \mathrm{C}$ for 15 days & {$[34]$} \\
\hline Corn + pullulanse & Precipitation & $\begin{array}{l}2.2 \mathrm{~N} \mathrm{HCl} \text { solution in the ratio of } 1: 2 \text {, heated } 12 \mathrm{~h} \\
\text { Neutralization with } 1 \mathrm{~N} \mathrm{NaoH}\end{array}$ & {$[35]$} \\
\hline Banana + aloe vera & Precipitation & $\begin{array}{l}\text { Ph maintained at 2.0, 3.0,4.0 and } 5.0 \\
\text { Incubation time: } 40,60,80 \text { and } 100 \mathrm{oC} \\
\text { Temperature: } 100 \mathrm{oC}\end{array}$ & {$[36]$} \\
\hline Quinoa & Precipitation & $\begin{array}{l}2.2 \mathrm{~N} \mathrm{HCl} \text { solution in the ratio of } 1: 2 \text {, heated } 12 \mathrm{~h} \\
\text { Neutralization with } 1 \mathrm{~N} \mathrm{NaoH}\end{array}$ & {$[35]$} \\
\hline Quinoa and maize & Ultrasounds & $\begin{array}{l}\text { Power: } 100 \mathrm{~W} \\
30 \text { cycles of sonication for I mint }\end{array}$ & {$[36]$} \\
\hline Araucaria angustifolia & $\begin{array}{l}\text { Ultrasounds } \\
\text { Acid hydrolysis }\end{array}$ & $\begin{array}{l}\text { Power: } 100 \mathrm{~W} \\
30 \text { cycles of sonication for I mint } \\
2 \mathrm{ml} / 100 \mathrm{ml} \mathrm{HCl} \text { for } 50 \text { days at } 22 \text { oC }\end{array}$ & {$[36]$} \\
\hline
\end{tabular}

Response surface methods were used to optimize the conditions of acid hydrolysis to form starch nanocrystals and optimize the impact of acids and the final yield of nanocrystals [15]. It was observed that sulfuric acid hydrolysis produces starch at a large scale compared to $\mathrm{HCl}$ hydrolysis, which produces different starch nanocrystals with low yield quality and takes maximum time to complete the process. It also has less potential to be utilized as a nanofiller. The concentration of acid, acid type, time, and temperature are the main conditions affecting hydrolysis, while the source of starch also affects hydrolysis. The kinetics of hydrolysis is affected by the type of acid and source of starch and divided kinetics into two steps: Step 1 involves hydrolysis at a fast rate, while in step 2, hydrolysis is completed at a slow rate [16]. The stability and distribution are increased due to sulfate formation but reduce the thermal stability of nanocrystals by using the $\mathrm{H}_{2} \mathrm{SO}_{4}$ hydrolysis method. Therefore, adding $0.5 \%$ ammonia $(0.5 \%)$ to $\mathrm{H}_{2} \mathrm{SO}_{4}$ starch slurry prior to centrifugation enhances the thermal stability of the nanocrystals [17].

3.1.1.2 Enzymatic hydrolysis Enzymes such as $\alpha$-amylase, $\beta$-amylase, and glucoamylase are utilized to synthesize starch nanocrystals. It was suggested that utilization of the $\alpha$-amylase enzyme for hydrolyzing natural starch at $37^{\circ} \mathrm{C}$ for $24 \mathrm{~h}$ at $150 \mathrm{rpm}$ formed starch nanocrystals with a size of $500 \mathrm{~nm}$ [18]. a-amylase hydrolysis separates the amorphous regions present in the starch granules. Ultrasonication was used to provide stability in the resultant product. Potato starch, pea starch, waxy corn starch, and corn starch are some common sources of starch used to make nano starch crystals by enzyme hydrolysis [19].

3.1.1.3 Combined enzymatic and acid hydrolysis Both acids and enzymes together can be used in the development of starch nanoparticles, which reduces the duration of acid hydrolysis. Pretreatment with enzymes provides the path for acid to penetrate in granules, leading to easy hydrolysis of the amorphatic region. A two step kinetic process is followed by combined hydrolysis. Pretreatment of enzymes before $2 \mathrm{~h}$ of acid hydrolysis decreased the hydrolysis time from 23 to $5 \mathrm{~h}[20]$.

\subsubsection{The regeneration/nanoprecipitation process}

Nanoprecipitation is a method commonly used for the synthesis of amorphous starch nanoparticles. The process involves gelatinization of starch prior to precipitation. Starch nanocrystals were formed by nanoprecipitation, and the crystallinity was maintained through selective enzymatic hydrolysis [15]. Maize starch with a suspension of high amylose was heated in a water bath in $90 \%$ dimethyl sulfoxide (DMSO) for $24 \mathrm{~h}$ at $35^{\circ} \mathrm{C}$ followed by filtration, in which the filtration device was divided into two parts in which one part was filled with an exact amount of starch and another with butanol. The apparatus was placed in a heated air oven at $70^{\circ} \mathrm{C}$ for six days, followed by the collection of the precipitate centrifugation of the suspension and washing three times with $\mathrm{n}$-butanol. The yield obtained from this process was very low, 
as the maximum amount of starch was hydrolyzed during this process [21]. In another study, starch nanocrystals were synthesized by using the nanoprecipitation technique by using absolute ethanol for precipitation. The mixture of $\mathrm{NaOH}$ and urea is used as a solvent for the dissolution of starch. A gently measured amount of absolute ethanol was added and stirred, followed by centrifugation, washing with ethanol, and then the collection of starch nanoparticles [22].

\subsubsection{Physical methods for starch nanoparticle/starch nanocrystal development}

3.1.3.1 Reactive extrusion The physicochemical and structural properties of starch are altered by subjecting it to the highest pressure, temperature, and shear [23]. The first patent was filed to prepare starch nanoparticles through a process called reactive extrusion using a twin-screw extruder that produces particles less than $400 \mathrm{~nm}$ in diameter. Another study was conducted in which starch nanocrystals were prepared by reactive extrusion utilizing a cross-linking agent, and the size of the nanoparticles obtained was $160 \mathrm{~nm}$ [24].

3.1.3.2 High-pressure homogenization Preparation of starch nanocrystals by high-pressure homogenization is an easy and eco-friendly method discovered by Liu and others in 2009. A homogenized slurry of starch is passed constantly through a microfluidizer. A reduction in particle size was observed from $5 \mu \mathrm{m}$ to $10-20 \mathrm{~nm}$ when starch suspensions of $5 \%$ were allowed to pass under pressure [25]. Starch nanocrystals have also been prepared combining cross-linking and high-pressure homogenization [26]. Another combination of homogenization and heat moisture developed nanocrystals yielding $80 \%$ final product with a diameter of $50 \mathrm{~nm}[15,27]$.

3.1.3.3 Using gamma radiation Gamma radiation is also used for the production of starch nanocrystals. This radiation will lead to cleavage of glycosidic linkages in starch, leading to the fragmentation of larger molecules at a very rapid rate. Free radicals are formed because small molecules such as dextrins are produced by the breakage of chemical bonds in starch. These starch nanocrystals produced from this process are vulnerable to heat degradation in comparison to natural starch [28].

3.1.3.4 Ultrasonication Sound waves within the frequency range of $15-20 \mathrm{kHz}$ are known as ultrasounds, and these waves are above human hearing. Ultrasonication was used to prepare starch nanoparticles derived from waxy maize starch suspensions. It was performed in a water bath at $8^{\circ} \mathrm{C}$ for $75 \mathrm{~min}$. The results obtained from SEM showed that the limiting size of starch nanocrystals obtained by ultrasonication was 30-100 nm. Parameters such as the concentration of starch, source, time, and temperature, as well as the power of sonication, affected the process of ultrasonication on starch [29]. Ultrasonication was used to synthesize starch nanoparticles from corn starch using a $20 \mathrm{kHz}$ sonicator with a power of $400 \mathrm{~W}$ coupled with a horn with a tip diameter of $13 \mathrm{~mm}$. The corn starch starch granules were suspended in a water-isopropanol solution, and the beaker was kept in a jacketed glass thermostatically controlled by a circulating water system at $10^{\circ} \mathrm{C}$ during sonication to obtain the corn starch nanoparticle [30].

\subsubsection{Applications of starch nanocrystals}

Nanotechnology has the potential to revolutionise the food packaging sector by providing materials with stronger tensile strength, higher moisture barrier, and more effective antibacterial properties [37]. In the packaging of the food industry, research and development are increasing with different ranges of films and nanocoating for various food products. The use of nanoparticles such as starch nanocrystals may change the development of packaging materials of food products with enhanced shelf life [38]. Starch nanocrystals can be utilized as catalysts for antioxidants, flavors, enzymes, and possess antimicrobial properties and anti-browning agents; these characteristics will help to extend shelf life [39]. The packaging of different foods has been made possible with starch nanocrystals due to their higher barrier properties, such as water vapor permeability and oxygen transfer rate. The water transmission rate is reduced by using starch nanocrystals from different botanical origins. Sorbitol-pullulan packaging films decrease the water vapor permeability and increase mechanical characteristics by adding 30-40\% starch nanocrystals [40] and adding maize starch nanocrystals to amaranth protein. The chemical and physical characteristics of pea starch films were induced by the addition of potato starch nanocrystals at different concentrations. Therefore, films incorporating starch nanocrystals had a maximum tensile strength and a lower water vapor permeability [41]. Cooked starch is used in paper making as an additive, but the starch paste viscosity increases upon cooking. The use of starch nanocrystals can reduce the viscosity compared to their natural starches and improve the overall performance of paper. The enzymatic browning and physicochemical properties of 
different fruits, e.g., apple, are decreased by starch-based nanocomposites [42]. Starch nanocrystals derived from cassava have been used with cinnamon oil and sodium bentonite nanoclay for the packaging of meatballs, and it was observed that microbial growth was reduced. Interestingly, starch nanocrystals incorporated with essential oils showed higher antioxidant activity than commercial plastic packaging materials. [43]

\subsubsection{The effect of nanocrystals on barrier properties}

Researchers have observed positive and satisfactory effects of utilizing starch nanocrystals as polymeric fillers. Nanocrystals have dimensions lower than $100 \mathrm{~nm}$, which results in better distribution and compactness of the structure of polymers. Both mechanical and barrier properties (water and gas permeability) are improved by incorporating starch nanocrystals. Water vapor permeability is reduced due to the compactness between polymeric structures, leading to water vapor diffusion. It was observed that both the water vapor permeability and water vapor transmission rate of starch nanocrystals were reduced significantly compared to those of normal pea starch. With the addition of $5 \%$ starch nanocrystals, the water vapor permeability was lowest, indicating enhanced barrier properties. A decrease in the oxygen transmission rate was observed in polylactic acid nanocomposites with starch nanocrystals as filler, preventing food degradation and spoilage inside the package [44]. Starch nanocrystals derived from waxy maize with $99 \%$ amylopectin have been proven to be a tremendous barrier to oxygen [45]. Starch nanocrystals from corn decrease water vapor permeability by $50 \%$, which may be due to interactions between hydrogen and covalent bonds among starch and polyphenolic compounds. These compounds and interactions inhibit the availability of hydrogen groups required to form hydrophilic bonds, therefore reducing the affinity of packaging films towards the water. The oxygen permeability of starch nanocrystals derived from corn starch was recorded as $12.11 \mathrm{~cm}^{3} \mu \mathrm{m} \mathrm{m}^{-2} \mathrm{~d}^{-1} \mathrm{kPa}^{-1}$, which indicates a good oxygen barrier. These values were increased compared to the study conducted by [46], who revealed a value of $4.34 \mathrm{~cm}^{3} \mu \mathrm{m} \mathrm{m}^{-2} \mathrm{~d}^{-1} \mathrm{kPa}^{-1}$ for nanocrystals derived from the quinoa-starch film. Differences between the starch nanocrystals films may be due to different modes of sample preparations, different types of sources/origins of starch, and differences in water content.

\subsubsection{Effect of nanocrystals on mechanical properties}

The two most important parameters that define mechanical characteristics are tensile strength (TS) and elongation at break (EB); both play a significant role in indicating the strength of films and their flexibility. The addition of starch nanocrystals induced tensile strength and Young's modulus compared to polylactic acid nanocomposites [47]. The highest tensile strength increased by $3 \%$, which was attributed to the improved interfacial adhesion between the starch nanocrystals and polymer matrix [48]. Lipid addition to rich starch nanocrystals increased the tensile strength while adding some oils, such as oleic acid, decreased the tensile strength when added at a ratio of 1:1. Interactions between the molecules can improve structural bonds among the polymer network. The addition of $5 \%$ starch nanocrystals increased, and the highest tensile strength of $9.96 \mathrm{Mpa}$, while elongation at break values was reduced to the minimum, i.e., $12.58 \%$. Improved mechanical properties may be attributed to the stiffness and dense structure of starch nanocrystals. The tensile strength is reduced when starch nanocrystals are added at 7-9\%, while the elongation at break values increases due to a large number of hydroxyl groups on the surface of the starch nanocrystals, which leads to separation of the microphage [49]. The mechanical properties of various Starch-based biodegradable films are presented in Table 2.

Table 2 Mechanical properties of various starch and starch nanoparticle based biodegradable film

\begin{tabular}{|c|c|c|c|c|c|}
\hline $\begin{array}{l}\text { Type of starch } \\
\text { nanocrystal }\end{array}$ & Composition of films & $\begin{array}{l}\text { Tensile } \\
\text { strength (MPa) }\end{array}$ & $\begin{array}{l}\text { \%age elon- } \\
\text { gation }\end{array}$ & Young's Modulus & Citation \\
\hline Corn & Starch-based biodegradable film & 14.22 & 5.26 & 13.47 & {$[50]$} \\
\hline Wheat & Wheat gluten films & 14.05 & 6.08 & 14.2 & {$[51]$} \\
\hline Potato & Polymeric pouches of different gas barrier properties & 14.57 & 70 & 14.44 & {$[52]$} \\
\hline Pea & Starch nanocrystals-reinforced pea starch films & 6.68 & 26.7 & 27.56 & [53] \\
\hline Maize & $\begin{array}{l}\text { Thermoplastic starch and polysaccharide nanocrystals } \\
\text { nanocomposites }\end{array}$ & 1.49 & 51 & 14.2 & {$[54]$} \\
\hline Rice & Composite films based on rice flour and cellulose fibers & 1.80 & 49 & 9.6 & [55] \\
\hline Tapioca & Tapioca starch based biodegradable polymer film & 0.78 & 137 & 0.8 & [56] \\
\hline
\end{tabular}




\subsection{Chitin nanoparticles}

Chitin is known as poly(b-(1-4)-N-acetyl-D-glucosamine), and it is a natural polysaccharide first discovered in 1884. It is the second most common biopolymer after cellulose Nature produces chitin as ordered crystalline microfibrils, found mainly in arthropod exoskeletons and fungi and yeast wall cells [57]. It is composed of extended long-chain $\mathrm{N}$-acetylglucosamine polymer-modified glucose [58]. Chitin nanocrystals (ChiNCs can be used as reinforcing nanofillers for biomedical polymers. Chitin has the ability to transform into individual nanocrystals by downsizing since arthropod shells have hierarchical structures. Acid hydrolysis and TEMPO-mediated oxidation are some methods used to make chitin nanocrystals [59].

\subsubsection{Acid hydrolysis}

The chitin powder was hydrolyzed in acid at $60^{\circ} \mathrm{Cand}$ vigorously stirred for $90 \mathrm{~min}$. We collected the residue by centrifugation and repeated the process two more times. A centrifuge was used to centrifuge the reaction mixture at $6000 \mathrm{rpm}$ for $20 \mathrm{~min}$, followed by multiple washes until turbidity was achieved. In the next step, we re-emulsified the precipitate using a homogenizer at 1000 for $10 \mathrm{~min}$ and then used ultrasonication for 5 min to disperse it in distilled water [60]

\subsubsection{TEMPO-mediated oxidation}

A new technique for oxidizing cellulose using TEMPO was recently discovered. Nanochitin can be rapidly prepared by using the TEMPO/NaBr/NaClO system in less than $2 \mathrm{~h}$ with $\mathrm{C} 6$-carboxylate groups of $0.40 * 0.60 \mathrm{mmol} / \mathrm{g}$. Chitin powder was disseminated in distal water (Ye et al., 2019). TEMPO and sodium bromide ( $\mathrm{NaBr} 2$ ) were added to the dispersion. The oxidation of chitin by TEMPO is initiated by the addition of $\mathrm{NaClO}$ solution. The $\mathrm{pH}$ of the dispersion was adjusted to 10 at room temperature by the addition of $0.5 \mathrm{M} \mathrm{NaOH}$ continuously. The reaction was stopped after the $\mathrm{NaOH}$ was no longer utilized by introducing a small amount of ethanol.The suspension could be collected by decanting after centrifuging at 10,000 rpm for $30 \mathrm{~min}$. The suspension was rinsed five times with ethanol after centrifugation $[59,61]$.

\subsection{Chitosan nanoparticle}

Chitosan is a polysaccharide derived from the chitin present in the cell wall of fungi and is deacetylated as a primary component. Chitosan is a cationic polymer consisting of (1-4)-2 amino-2-deoxy deoxy- $\beta$-D-glucan and has gained more attention because of its $\mathrm{pH}$ sensitivity, biocompatibility, and bioactive properties functions [62]. Chitosan nanoparticles were first defined by Ohya in 1994. He suggested intravenous fluorouracil delivery carried by nanoparticles prepared by emulsification and cross-linking [63]. In food applications, modified chitosan nanocrystals have provided the most emerging applications.

\subsubsection{Emulsification and crosslinking}

A chitosan nanoparticle was first developed by coupling amino groups of the chitosan molecules with aldehydic groups of cross-linking. In the cross-linking process, the cross-linking oil phase is used as a suspension that, depending on its physical properties, can vastly affect the morphology of the droplets, uniformity, and stability of the W/O emulsion [64]. The preparation of chitosan nanocrystals involves water in the oil emulsion followed by the addition of a cross-linking agent that hardens the formed droplets [63]. Water in oil is prepared by first emulsifying an aqueous chitosan solution in the oil phase and then stabilizing the droplet by using a surfactant, e.g., span 80 . Afterward, the stable emulsion was cross-linked with glutaraldehyde, the most versatile cross-linking agent. As a result, a covalent crosslinking reaction takes place between the amino group of chitosan and the aldehydic group of glutaraldehyde and precipitates into the particle. Separation and obtaining fine nanoparticles from emulsions can be achieved via centrifugation, multiple washing steps and vacuum or freeze-drying $[62,65]$. 


\subsubsection{Ionic gelation}

There are a number of methods available for preparing chitosan nanoparticles, but the ionic gelation technique has attracted considerable interest in nanoparticles, including [66]. Researchers have investigated chitosan nanoparticles since the 1990s, with ionic gelation being one of the most widely used methods for the preparation, described first by [67]. It depends on the ionic crosslinking between charges, the positively charged primary amino group of chitosan, and the negatively charged polyanion, e.g., sodium tripolyphosphate (TPP), as a cross-linking agent because of its nontoxicity and multivalent properties. In this process, a chitosan solution was formed by dissolving chitosan in acetic acid, and then the solution was stirred overnight in a magnetic stirrer at room temperature. Then, aqueous solutions of chitosan and TPP were mixed together under sonication at room temperature in a dropwise manner. After mixing, the $\mathrm{pH}$ of the suspension to 7 was adjusted using sodium hydroxide. Through centrifugation at $1200 \mathrm{rpm}$, the formed particles were separated and washed with water three times. For characterization, nanoparticles were freeze-dried and stored at $4^{\circ}$ in a dark atmosphere [68].

\subsubsection{Reverse micellization}

The first reports of chitosan nanoparticles made from reverse micelles were published by [69]. A reverse micelle is a droplet of water in oil stabilized by a surfactant, e.g., sodium 2 bis (2-ethylhexyl) sulfosuccinate cetyltrimethylammonium bromide used as a surfactant and called Na (AOT). In the method of reverse micellization, a lipophilic surfactant is dissolved in a suitable organic solvent, such as n-hexane, to prepare a W/O microemulsion. In another step, the aqueous phase containing chitosan, the drug, and glutaraldehyde is brought over the organic phase at constant stirring, and reverse micelles take place at this step. Further nanoparticles were separated by evaporation using a rotary evaporator $[63,70]$.

\subsection{Alginate nanoparticles}

Alginate is obtained from the cell wall of brown algae, is a natural polysaccharide, and easily gelates with $\mathrm{Ca}+$. A wide variety of bio-applications rely on particle forms, including drug delivery systems [71, 72], food processing [73], enzyme immobilization, and biosensor engineering techniques [74]. A comprehensive review has been conducted on alginate's physical and chemical properties and its use in the production of particles and bulk gels [75]. It is biodegradable, costeffective, mucoadhesive, biocompatible, and nanoimmunogenic It can even be produced in large quantities at inexpensive prices [76]. Two methods are used to prepare alginate nanoparticles: the complexation method and the w/o emulsification method. Systems ranging in size from 10 to $1000 \mathrm{~nm}$ are referred to as nanoaggregates, nanocapsules, and nanospheres.

\subsubsection{Complexation method}

The formation of alginate nanoparticles can occur via polyelectrolyte complexation in mild aqueous environments unaffected by organic solvents. To make a Ca-alginate pregel solution, a 1:1 (volume ratio) mixture of alginate and calcium chloride solution was prepared. To increase the uniformity of the pregel, calcium chloride $(\mathrm{CaCl} 2)$ solution was added dropwise to the alginate solution during sonication for $30 \mathrm{~s}$ at $120 \mathrm{~W}$. Then different dilutions of the cationic polymer were added, such as poly L-lysine and chitosan, through ionic interactions to form nanoparticles. However, the conventional mixing of Ca-alginate pregels with cationic polymers results in wider particle sizes, and microaggregates are formed, preventing their use as functional particles [12]

\subsubsection{Emulsification method}

As a part of the emulsification process, alginate is deposited on the interface droplets, and stabilizing methods include chemical and physical intramolecular cross-linking, followed by solvent removal. Alginate nanoparticles were synthesized by emulsification with external gelation. An aqueous solution of alginate mixed with oil containing Span 80 was homogenized to achieve emulsification and sonicated for $10 \mathrm{~min}$. A solution of calcium chloride (with or without chitosan) was gradually added to the emulsion to stabilize the nanoparticles. It was observed that the combination of calcium chloride 
and chitosan results in significantly larger nanoparticles than nanoparticles without chitosan [77, 78]. A number of factors affect the size and loading capacity of nanoparticles, including the type of oil phase, order of addition of chitosan and calcium chloride, the addition of surfactant, and the amount of mixing energy during fabrication [79]

\title{
4 Techno economic challenges in polysaccharide-based bionanocomposite films
}

There are numerous challenges and hurdles associated with the various phases of the development of nanoparticles. To achieve a consistent product with the intended physicochemical characteristics and biological behaviors, nanoparticles must be designed and engineered with care, have detailed orthogonal analytical methods, and be scaled up proportionally. The disadvantages of nanocomposite formulation include increased viscosity, dispersion difficulties, optical challenges, and increased sedimentation rate. The properties of polysaccharide-based nanocomposite films are determined by the kind of nanoparticle, the degree of dispersion, and the concentration of nanoparticles in a polymer matrix. The miscibility and compatibility of nanoparticles in the biopolymer solution are critical for achieving the appropriate characteristics for food packaging applications. A relatively emerging concern relating to the safety of food packaging materials is connected to nanosized material, which may inflow into the food items when contact duration is increased. Storage temperature also greatly influenced the infusion of nanoparticles into the food product. The health risk associated with nanocomposite films depends on the rate of migration of nanomaterials from outer packaging into food and the toxicity of the nanomaterials employed. Migration testing, cytotoxicity testing, and eco-toxicity testing are required to determine the environmental implications of nanomaterials used in food packaging prior to extensive use of these materials. In addition to these, more investigations are needed to solve issues relating to mechanical, thermal, moisture and gas barrier properties of the polysaccharide-based nanocomposite films for food packaging applications.

\section{Conclusions}

Packaging materials such as petroleum-based plastics are responsible for the maximum portion of environmental waste and can be replaced by biodegradable nanomaterials such as starch, chitin, alginate, and chitosan. These biodegradable nanomaterial based packaging materials must be safe in addition to safeguarding the food from dirt or dust, air, light, moisture, and pathogenic germs. Under its intended circumstances of usage, the packaging should be inert, inexpensive to create, lightweight, and capable of withstanding harsh conditions during processing or filling. These food packaging has to be be resistant to a variety of storage temperature and relative humidity of environment. The different studies showed that incorporating nanomaterials in biodegradable polymers can enhance the gas and water vapour barrier functions and improve mechanical properties. Migration and permeability to ambient gases, water vapour, or natural compounds contained inside the food being packed is a major concern in food packaging. Thus, further studies are required to optimise the migration and permeability to ambient gases, water vapour, or natural substances through the packaging material, as well as to determine the toxicity of nanomaterials that may be incorporated into food items.

\begin{abstract}
Authors' contributions AA formulated the whole manuscript.ZU drafted and formulated the tables and figures.AHD refined the whole manuscript by improving the language and technical writing.KKD drafted the outline of the manuscript. All authors read and approved the final manuscript.
\end{abstract}

\section{Declarations}

Competing interests The authors declare no competing interests.

Open Access This article is licensed under a Creative Commons Attribution 4.0 International License, which permits use, sharing, adaptation, distribution and reproduction in any medium or format, as long as you give appropriate credit to the original author(s) and the source, provide a link to the Creative Commons licence, and indicate if changes were made. The images or other third party material in this article are included in the article's Creative Commons licence, unless indicated otherwise in a credit line to the material. If material is not included in the article's Creative Commons licence and your intended use is not permitted by statutory regulation or exceeds the permitted use, you will need to obtain permission directly from the copyright holder. To view a copy of this licence, visit http://creativecommons.org/licenses/by/4.0/. 


\section{References}

1. Enescu D, Cerqueira MA, Fucinos P, Pastrana LM. Recent advances and challenges on applications of nanotechnology in food packaging. A literature review. Food Chem Toxicol. 2019;134:110814. https://doi.org/10.1016/j.fct.2019.110814.

2. Sharma C, Dhiman R, Rokana N, Panwar H. Nanotechnology: an untapped resource for food packaging. Front Microbiol. $2017 ; 8: 1735$. https://doi.org/10.3389/fmicb.2017.01735.

3. Adeyeye SAO. Food packaging and nanotechnology: safeguarding consumer health and safety. Nutr Food Sci. 2019. https://doi.org/10. 1108/NFS-01-2019-0020.

4. Huang Y, Mei L, Chen X, Wang Q. Recent developments in food packaging based on nanomaterials. Nanomaterials. 2018;8(10):830. https:// doi.org/10.3390/nano8100830.

5. Mishra RK, Ha SK, Verma K, Tiwari SK. Recent progress in selected bionanomaterials and their engineering applications: an overview. J Sci. 2018;3(3):263-88. https://doi.org/10.1016/j.jsamd.2018.05.003.

6. Tosif MM, Najda A, Bains A, Kaushik R, Dhull SB, Chawla P, Walasek-Janusz M. A comprehensive review on plant-derived mucilage: characterization, functional properties, applications, and its utilization for nanocarrier fabrication. Polymers. 2021;13(7):1066.

7. Chawla P, Najda A, Bains A, Nurzyńska-Wierdak R, Kaushik R, Tosif MM. Potential of gum arabic functionalized iron hydroxide nanoparticles embedded cellulose paper for packaging of paneer. Nanomaterials. 2021;11(5):1308.

8. Hao Y, Chen Y, Li Q, Gao Q. Synthesis, characterization and hydrophobicity of esterified waxy potato starch nanocrystals. Ind Crops Prod. 2019;130:111-7. https://doi.org/10.1016/j.indcrop.2018.12.073.

9. Santana JS, de Carvalho Costa ÉK, Rodrigues PR, Correia PRC, Cruz RS, Druzian JI. Morphological, barrier, and mechanical properties of cassava starch films reinforced with cellulose and starch nanoparticles. J Appl Polym Sci. 2019;136(4):47001.

10. Xu C, Chen C, Wu D. The starch nanocrystal filled biodegradable poly ( $\varepsilon$-caprolactone) composite membrane with highly improved properties. Carbohyd Polym. 2018;182:115-22.

11. Oliveira AV, da Silva APM, Barros MO, de sá M. Souza Filho, M., Rosa, M. F., \& Azeredo, H. M. Nanocomposite films from mango kernel or corn starch with starch nanocrystals. Starch-Stärke. 2018;70(11-12):1800028.

12. Kim HY, Park SS, Lim ST. Preparation, characterization and utilization of starch nanoparticles. Colloids Surf, B. 2015;126:607-20. https:// doi.org/10.1016/j.colsurfb.2014.11.011.

13. Dai L, Li C, Zhang J, Cheng F. Preparation and characterization of starch nanocrystals combining ball milling with acid hydrolysis. Carbohyd Polym. 2018;180:122-7. https://doi.org/10.1016/j.carbpol.2017.10.015.

14. Saeng-On J, Aht-Ong D. Production of starch nanocrystals from agricultural materials using mild acid hydrolysis method: optimization and characterization. Polym Renew Resour. 2017;8(3):91-116. https://doi.org/10.1177/204124791700800302.

15. Liu C, Li K, Li X, Zhang M, Li J. Formation and structural evolution of starch nanocrystals from waxy maize starch and waxy potato starch. Int J Biol Macromol. 2021;180:625-32. https://doi.org/10.1016/j.jbiomac.2021.03.115.

16. Bakhtiari, F., Elnashaie, S. S. E., Danafar, F., \& Kamali, F. (2018, April). A Statistical Study on the Parameters Influences the Formation of Starch Nanoparticles through Acid Hydrolysis. In The International Conference on Chemical and Environmental Engineering (pp. 232-238). Military Technical College. Doi: https://doi.org/10.21608/ICCEE.2018.34666

17. Jo, M. (2017). Improving productivity of starch nanocrystals (SNC) using sonication and characteristics of SNC-stabilized Pickering emulsions (Doctoral dissertation, 서울 대 학 교 대 학 원). Doi: https://doi.org/10.1016/j.aiepr.2019.11.003

18. Wang S, Copeland L. Effect of acid hydrolysis on starch structure and functionality: a review. Crit Rev Food Sci Nutr. 2015;55(8):1081-97. https://doi.org/10.1080/10408398.2012.684551.

19. Dai L, Zhang J, Cheng F. Succeeded starch nanocrystals preparation combining heat-moisture treatment with acid hydrolysis. Food Chem. 2019;278:350-6. https://doi.org/10.1016/j.foodchem.2018.11.018.

20. Le Corre D, Bras J, Choisnard L, Dufresne A. Optimization of the batch preparation of starch nanocrystals to reach daily time-scale. StarchStärke. 2012;64(6):489-96. https://doi.org/10.1002/star.201100145.

21. Kumari S, Yadav BS, Yadav RB. Synthesis and modification approaches for starch nanoparticles for their emerging food industrial applications: a review. Food Res Int. 2020;128:108765. https://doi.org/10.1016/j.foodres.2019.108765.

22. Le Corre D, Angellier-Coussy H. Preparation and application of starch nanoparticles for nanocomposites: a review. React Funct Polym. 2014;85:97-120. https://doi.org/10.1016/j.reactfunctpolym.2014.09.020.

23. Giezen, F., Jongboom, R., Gotlieb, K. and Boersma, A., Wo 00/69916. WO 00/69916. 2000.

24. Gutiérrez TJ, Valencia GA. Reactive extrusion-processed native and phosphated starch-based food packaging films governed by the hierarchical structure. Int J Biol Macromol. 2021;172:439-51. https://doi.org/10.1016/j.ijbiomac.2021.01.048.

25. Liu D, Wu Q, Chen H, Chang PR. Transitional properties of starch colloid with particle size reduction from microto nanometer. J Colloid Interface Sci. 2009;339(1):117-24. https://doi.org/10.1016/j.jcis.2009.07.035.

26. Shi AM, Li D, Wang LJ, Li BZ, Adhikari B. Preparation of starch-based nanoparticles through high-pressure homogenization and miniemulsion cross-linking: Influence of various process parameters on particle size and stability. Carbohyd Polym. 2011;83(4):1604-10.

27. Park EY, Kim MJ, Cho M, Lee JH, Kim JY. Production of starch nanoparticles using normal maize starch via heat-moisture treatment under mildly acidic conditions and homogenization. Carbohyd Polym. 2016;151:274-82. https://doi.org/10.1016/j.carbpol.2016.05.056.

28. Lamanna M, Morales NJ, García NL, Goyanes S. Development and characterization of starch nanoparticles by gamma radiation: potential application as starch matrix filler. Carbohyd Polym. 2013;97(1):90-7. https://doi.org/10.1016/j.carbpol.2013.04.081.

29. Haaj SB, Magnin A, Pétrier C, Boufi S. Starch nanoparticles formation via high power ultrasonication. Carbohyd Polym. 2013;92(2):1625-32. https://doi.org/10.1016/j.carbpol.2012.11.022.

30. Boufi S, Haaj SB, Magnin A, Pignon F, Impéror-Clerc M, Mortha G. Ultrasonic assisted production of starch nanoparticles: structural characterization and mechanism of disintegration. Ultrason Sonochem. 2018;41:327-36.

31. Lin N, Huang J, Chang PR, Anderson DP, Yu J. Preparation, modification, and application of starch nanocrystals in nanomaterials: a review. J Nanomater. 2011. https://doi.org/10.1155/2011/573687. 
32. Pratiwi M, Faridah DN, Lioe HN. Structural changes to starch after acid hydrolysis, debranching, autoclaving-cooling cycles, and heat moisture treatment (HMT): a review. Starch-Stärke. 2018;70(1-2):1700028. https://doi.org/10.1002/star.201700028.

33. Zhang $\mathrm{H}$, Hou H, Liu P, Wang W, Dong H. Effects of acid hydrolysis on the physicochemical properties of pea starch and its film forming capacity. Food Hydrocolloids. 2019;87:173-9. https://doi.org/10.1016/j.jfoodeng.2016.03.021.

34. Martins PC, Gutkoski LC, Martins VG. Impact of acid hydrolysis and esterification process in rice and potato starch properties. Int J Biol Macromol. 2018;120:959-65. https://doi.org/10.1016/j.ijbiomac.2018.08.170.

35. Kasim, A. (2020, March). Preparation and characterization of sago (metroxylon sp.) Starch nanoparticles using hydrolysis-precipitation method. In Journal of Physics: Conference Series (Vol. 1481, No. 1, p. 012021). IOP Publishing.

36. Goncalves PM, Noreña CPZ, da Silveira NP, Brandelli A. Characterization of starch nanoparticles obtained from Araucaria angustifolia seeds by acid hydrolysis and ultrasound. LWT-Food Sci Technol. 2014;58(1):21-7. https://doi.org/10.1016/j.lwt.2014.03.015.

37. Pathakoti K, Manubolu M, Hwang HM. Nanostructures: current uses and future applications in food science. J Food Drug Analysis. 2017;25(2):245-53. https://doi.org/10.1016/j.jfda.2017.02.004.

38. Sothornvit R. Nanostructured materials for food packaging systems: new functional properties. Curr Opin Food Sci. 2019;25:82-7. https://doi.org/10.1016/j.cofs.2019.03.001.

39. Li C, Sun P, Yang C. Emulsion stabilized by starch nanocrystals. Starch-Stärke. 2012;64(6):497-502. https://doi.org/10.1002/star.20110 0178.

40. Sumit G. Nanotechnology in food packaging a critical review. Russian J Agric Socio-Econ Sci. 2012;10:10.

41. Jiang S, Liu C, Wang X, Xiong L, Sun Q. Physicochemical properties of starch nanocomposite films enhanced by self-assembled potato starch nanoparticles. LWT-Food Sci Technol. 2016;69:251-7. https://doi.org/10.1016/j.lwt.2016.01.053.

42. Azevedo VM, Dias MV, de Siqueira Elias HH, Fukushima KL, Silva EK, Carneiro JDD, et al. Effect of whey protein isolate films incorporated with montmorillonite and citric acid on the preservation of fresh-cut apples. Food Res Int. 2018;107:306-13. https://doi.org/ 10.1016/j.foodres.2018.02.050.

43. lamareerat B, Singh M, Sadiq MB, Anal AK. Reinforced cassava starch based edible film incorporated with essential oil and sodium bentonite nanoclay as food packaging material. J Food Sci Technol. 2018;55(5):1953-9. https://doi.org/10.1007/s13197-018-3100-7.

44. Arrieta MP, Fortunati E, Dominici F, López J, Kenny JM. Bionanocomposite films based on plasticized PLA-PHB/cellulose nanocrystal blends. Carbohyd Polym. 2015;121:265-75. https://doi.org/10.1016/j.carbpol.2014.12.056.

45. Arrieta MP, Fortunati E, Dominici F, Rayón E, López J, Kenny JM. Multifunctional PLA-PHB/cellulose nanocrystal films: processing, structural and thermal properties. Carbohyd Polym. 2014;107:16-24. https://doi.org/10.1016/j.carbpol.2014.02.044.

46. Araujo-Farro PC, Podadera G, Sobral PJ, Menegalli FC. Development of films based on quinoa (Chenopodium quinoa, Willdenow) starch. Carbohyd Polym. 2010;81(4):839-48.

47. Mehyar GF, Al-Ismail K, Han JH, Chee GW. Characterization of edible coatings consisting of pea starch, whey protein isolate, and carnauba wax and their effects on oil rancidity and sensory properties of walnuts and pine nuts. J Food Sci. 2012;77(2):E52-9. https:// doi.org/10.1111/j.1750-3841.2011.02559.x.

48. Chen CJ, Shen YC, Yeh Al. Physico-chemical characteristics of media-milled corn starch. J Agric Food Chem. 2010;58(16):9083-91. https://doi.org/10.1021/jf1020945.

49. García NL, Ribba L, Dufresne A, Aranguren M, Goyanes S. Effect of glycerol on the morphology of nanocomposites made from thermoplastic starch and starch nanocrystals. Carbohyd Polym. 2011;84(1):203-10. https://doi.org/10.1016/j.carbpol.2010.11.024.

50. Jiang T, Duan Q, Zhu J, Liu H, Yu L. Starch-based biodegradable materials: challenges and opportunities. Adv Industr Eng Polym Res. 2020;3(1):8-18. https://doi.org/10.1016/j.aiepr.2019.11.003.

51. Hager AS, Vallons KJ, Arendt EK. Influence of gallic acid and tannic acid on the mechanical and barrier properties of wheat gluten films. J Agric Food Chem. 2012;60(24):6157-63. https://doi.org/10.1021/jf300983m.

52. Zhang H, Tang Z, Rasco B, Tang J, Sablani SS. Shelf-life modeling of microwave-assisted thermal sterilized mashed potato in polymeric pouches of different gas barrier properties. J Food Eng. 2016;183:65-73. https://doi.org/10.1016/j.jfoodeng.2016.03.021.

53. Li X, Qiu C, Ji N, Sun C, Xiong L, Sun Q. Mechanical, barrier and morphological properties of starch nanocrystals-reinforced pea starch films. Carbohyd Polym. 2015;121:155-62. https://doi.org/10.1016/j.carbpol.2014.12.040.

54. Gonzalez K, Iturriaga L, Gonzalez A, Eceiza A, Gabilondo N. Improving mechanical and barrier properties of thermoplastic starch and polysaccharide nanocrystals nanocomposites. Eur Polymer J. 2020;123:109415. https://doi.org/10.1016/j.eurpolymj.2019.109415.

55. Dias AB, Müller CM, Larotonda FD, Laurindo JB. Mechanical and barrier properties of composite films based on rice flour and cellulose fibers. LWT-Food Sci Technol. 2011;44(2):535-42. https://doi.org/10.1016/j.Iwt.2010.07.006.

56. Prabha PH, Ranganathan TV. Process optimization for evaluation of barrier properties of tapioca starch based biodegradable polymer film. Int J Biol Macromol. 2018;120:361-70. https://doi.org/10.1016/j.ijbiomac.2018.08.100.

57. Rinaudo M. Chitin and chitosan: properties and applications. Prog Polym Sci. 2006;31(7):603-32. https://doi.org/10.1016/j.progp olymsci.2006.06.001.

58. Ahmad A, Mubharak NM, Naseem K, Tabassum H, Rizwan M, Najda, et al. Recent advancement and development of chitin and chitosan-based nanocomposite for drug delivery: critical approach to clinical research Arab. J Chem. 2020;13:8935-64. https://doi. org/10.1016/j.arabjc.2020.10.019.

59. Salaberria AM, Labidi J, Fernandes SC. Chitin nanocrystals and nanofibers as nanosized fillers into thermoplastic starch-based biocomposites processed by melt-mixing. Chem Eng J. 2014;256:356-64.

60. Wang X, Liang K, Tian Y, Ji Y. A facile and green emulsion casting method to prepare chitin nanocrystal reinforced citrate-based bioelastomer. Carbohyd Polym. 2017;157:620-8. https://doi.org/10.1016/j.carbpol.2016.10.034.

61. Ifuku S, Hori T, Izawa H, Morimoto M, Saimoto H. Preparation of zwitterionically charged nanocrystals by surface TEMPO-mediated oxidation and partial deacetylation of a-chitin. Carbohyd Polym. 2015;122:1-4. https://doi.org/10.1016/j.carbpol.2014.12.060.

62. Yanat M, Schroën K. Preparation methods and applications of chitosan nanoparticles; with an outlook toward reinforcement of biodegradable packaging. React Funct Polym. 2021. https://doi.org/10.1016/j.reactfunctpolym.2021.104849.

63. Grenha A. Chitosan nanoparticles: a survey of preparation methods. J Drug Target. 2012;20(4):291-300. https://doi.org/10.3109/ $1061186 X .2011 .654121$. 
64. Zhang K, Xu Y, Lu L, Shi C, Huang Y, et al. Hydrodynamic cavitation: A feasible approach to intensify the emulsion cross-linking process for chitosan nanoparticle synthesis. Ultrason Sonochem. 2021;74: 105551. https://doi.org/10.1016/j.ultsonch.2021.105551.

65. Ribeiro EF, de Barros-Alexandrino TT, Assis OBG, Junior AC, Quiles A, Hernando I, Nicoletti VR. Chitosan and crosslinked chitosan nanoparticles: synthesis, characterization and their role as Pickering emulsifiers. Carbohyd Polym. 2020;250: 116878. https://doi. org/10.1016/j.carbpol.2020.116878.

66. Fan L, Luo C, Sun M, Li X, Lu F, Qiu H. Preparation of novel magnetic chitosan/graphene oxide composite as effective adsorbents toward methylene blue. Biores Technol. 2012;114:703-6.

67. Calvo P, Remuñan-López C, Vila-Jato JL, Alonso MJ. Chitosan and chitosan/ethylene oxide-propylene oxide block copolymer nanoparticles as novel carriers for proteins and vaccines. Pharm Res. 1997;14(10):1431-6.

68. Anandhakumar S, Krishnamoorthy G, Ramkumar KM, Raichur AM. Preparation of collagen peptide functionalized chitosan nanoparticles by ionic gelation method: an effective carrier system for encapsulation and release of doxorubicin for cancer drug delivery. Mater Sci Eng C. 2017;70:378-85.

69. Mitra S, Gaur U, Ghosh PC, Maitra AN. Tumour targeted delivery of encapsulated dextran-doxorubicin conjugate using chitosan nanoparticles as carrier. J Control Release. 2001;74(1-3):317-23.

70. Pileni MP. Reverse micelles used as templates: a new understanding in nanocrystal growth. J Exp Nanosci. 2006;1(1):13-27. https://doi. org/10.1080/17458080500462075.

71. Lee KY, Mooney DJ. Alginate: properties and biomedical applications. Prog Polym Sci. 2012;37(1):106-26. https://doi.org/10.1016/j.progp olymsci.2011.06.003.

72. Sun L, Zhou S, Wang W, Li X, Wang J, Weng J. Preparation and characterization of porous biodegradable microspheres used for controlled protein delivery. Colloids Surfaces A. 2009;345(1-3):173-81. https://doi.org/10.1016/j.colsurfa.2009.04.053.

73. Malone ME, Appelqvist IA. Gelled emulsion particles for the controlled release of lipophilic volatiles during eating. J Control Release. 2003;90(2):227-41. https://doi.org/10.1016/S0168-3659(03)00179-2.

74. Kang DH, Jung HS, Ahn N, Yang SM, Seo S, et al. Janus-compartmental alginate microbeads having polydiacetylene liposomes and magnetic nanoparticles for visual lead (II) detection. ACS Appl Mater Interfaces. 2014;6(13):10631-7.

75. Tønnesen HH, Karlsen J. Alginate in drug delivery systems. Drug Dev Ind Pharm. 2002;28(6):621-30. https://doi.org/10.1081/DDC-12000 3853.

76. Yang JS, Xie YJ, He W. Research progress on chemical modification of alginate: a review. Carbohyd Polym. 2011;84(1):33-9. https://doi. org/10.1016/j.carbpol.2010.11.048.

77. Nayak, A. K., \& Hasnain, M. S. (2020). lonotropically gelled alginate particles in sustained drug release. In Alginates in Drug Delivery (pp. 203-230). Academic Press. Doi: https://doi.org/10.1016/B978-0-12-817640-5.00009-1

78. Hasnain, M. S., Nayak, A. K., Kurakula, M., \& Hoda, M. N. (2020). Alginate nanoparticles in drug delivery. In Alginates in Drug Delivery (pp. 129-152). Academic Press. Doi: https://doi.org/10.1016/B978-0-12-817640-5.00006-6

79. Masalova O, Kulikouskaya V, Shutava T, Agabekov V. Alginate and chitosan gel nanoparticles for efficient protein entrapment. Phys Procedia. 2013;40:69-75. https://doi.org/10.1016/j.phpro.2012.12.010.

Publisher's Note Springer Nature remains neutral with regard to jurisdictional claims in published maps and institutional affiliations. 